\title{
The Development of a Computer-Based Teaching Simulation Tool to Aid Medical Imaging Educators in Teaching Pattern Recognition
}

\author{
Desarrollo de una Herramienta de Simulación Computacional de Enseñanza de Apoyo \\ a los Educadores de Imagen Médica en la Enseñanza del Patrón de Reconocimiento
}

Sibusiso Mdletshe ${ }^{1,2}$ \& Marcus Oliveira ${ }^{3}$

MDLETSHE, S. \& OLIVEIRA, M. The development of a computer-based teaching simulation tool to aid Medical Imaging educators in teaching pattern recognition. Int. J. Morphol., 38(5):1258-1265, 2020.

SUMMARY: The aim of this exploratory design science research (DSR) study was to design a computer-based teaching simulation tool (CBTST) for training medical imaging (MI) students in chest pattern recognition. A DSR methodology used in the design of the CBTST entailed the following phases: 1) awareness of the problem (proposal design); 2) suggestion; 3) development; 4) evaluation; and 5) conclusion. The CBTST was designed using Microsoft Visual Studio which operates on the Structured Query Language server. The designed CBTST was evaluated using the System Usability Scale (SUS) and MI educators. The designed CBTST evaluation yielded an average score of 70.1 which exceeded the score of 68 which is generally accepted to indicate that the CBTST has good usability. The CBTST proved to be an authentic tool that is user-friendly and allows communication and feedback between the educator and the students. It is envisaged that the implementation of this tool will enhance the future training of MI students in pattern recognition while contributing immensely to the current development of the use of computer-based simulation.

KEY WORDS: Pattern recognition; Software development; Computer-based teaching simulation; Medical imaging; Implicit skills.

\section{INTRODUCTION}

Medical Imaging (MI) is a dynamic field which has experienced significant technological advancements in recent years. The advancements have kept abreast with the developments seen in the field of information technology which has allowed for significant progress in the way in which diagnostic radiographers capture, process and share images (European Society of Radiology 2009, 2010; Fornell, 2012; Herring, 2016). During undergraduate studies, students are taught basic pattern recognition skills, especially for the commonly requested examinations e.g. chest radiographs. Chest radiographs are amongst the most difficult to interpret examinations due to a variety of changes that can manifest in the respiratory system (Rockall et al., 2014).

Pattern recognition skills can be classified as implicit skills, which are skills that are acquired through the process of repetitive stimulus-response binding (Chen et al., 2017). Implicit skills can be taught in the virtual or simulated environments. It is for this reason that the use of computerbased teaching simulation in health education, inclusive of
MI, has gained the upper hand (Jones et al., 2015; Shanahan, 2016; Malathi et al., 2016).

In order to support the use of computer-based teaching simulation in MI, it is necessary to design contextrelated teaching simulation tools. In the MI context, such tools must develop the pattern recognition skills of students using a systematic approach that is combined with the advantages derived from the advances in technology. An added advantage of such a tool would be the ability to teach and assess these skills outside of the clinical environment that would reduce the training burden currently placed on resource-stretched clinical facilities. This is supported by Shanahan who postulates that simulation is one of the approaches that can be used to teach clinical skills.

There is still a gap regarding CBTST developed for teaching pattern recognition skills to enhance implicit skills at MI undergraduate level, that are also capable of providing feedback, correction and affirmation as a live tool. While

\footnotetext{
${ }^{1}$ Department of Medical Imaging and Radiation Sciences, University of Johannesburg, South Africa.

${ }^{2}$ Department of Anatomy and Medical Imaging, University of Auckland, New Zealand.

${ }^{3}$ Department of Health Technology and Biology, Federal Institute of Bahia, Salvador (BA), Brazil.
} 
there may be software packages and CBTST already available to teach pattern recognition, there are several advantages of custom-designed software packages, one of which is that it allows for the creation of a tailor-made solution for the needs of that organisation. Since the plain chest radiographs are most frequently requested imaging modality in the diagnosis of various diseases (Eisenberg \& Johnson, 2015), this exploratory study was conducted to address this gap with the aim of designing a context related CBTST for training undergraduate MI students in chest pattern recognition.

\section{MATERIAL AND METHOD}

The study was conducted at a university in Johannesburg, South Africa, as a collaborative project between a Department in the Faculty of Health Sciences and a Department in the Faculty of Engineering and the Built Environment. The study used the design science research (DSR) methodology that is generally used in the information systems field. This methodology was considered suitable as its philosophical assumptions allowed for a collaborative research process to generate new knowledge through creative manipulation of the design needs of the CBTS that was being developed. The DSR methodology incorporated awareness of the problem, suggestion, development, evaluation and conclusion (Fig. 1) (Vaishnavi et al., 2019). This paper focuses on the development, evaluation and conclusion phases of the study.

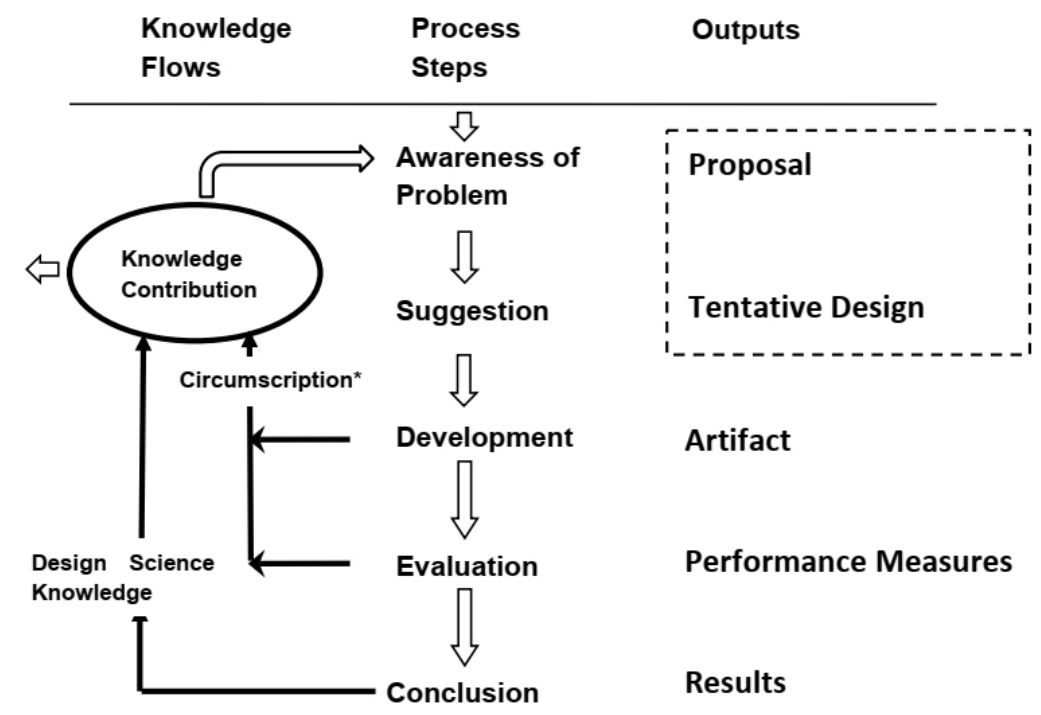

*Circumscription is discovery of constraint knowledge about theories gained through detection and analysis of contradictions when things do not work according to theory.

Fig. 1. DSR Process Model (Vaishnavi et al., 2019).
Development phase. This phase entailed the actual development of the CBTST using the product design specifications that were the output of the suggestion phase. The suggestion phase had yielded the software requirements specification (SRS) document that informed the design of the CBTST called ProtoRad.

The CBTST was developed using Microsoft Visual Studio 2013, which operates on the Structured Query Language (SQL) server expressly for database management. SQL is a standardised coding / programming language used for managing relational databases and performing various operations on the data in them (Pesapane, 2018). The various added tool units within the CBTST were based on commonly available codes, e.g. the edge detection modules were based on typical OpenCV implementations of the edge detectors (Pesapane).

Non-functional requirements. The performance requirements entailed that the CBTST had to be able to operate consistently while being compatible with different packages/equipment vendors to allow it to be used on various digital platforms. The CBTST was also designed to have automatic continuous backup to ensure that work already done by any user was always retained and not lost.

The chest radiographs used in this study included the selection from the Japanese Society of Radiological Technology, available for public use with regards to research and education (Shiraishi, 2000). In addition, a few digitized radiographs were sourced from local teaching materials (university where the study was located).

Tutorial Plans. Examples of tutorial plans that can be loaded in ProtoRad are given to indicate the span of performance that can be achieved in terms of the stated goal of providing an automated tutoring system for teaching pattern recognition to MI students.

Tutorial 1: Image pre-reading. This tutorial focuses on teaching the student how to evaluate the image for technical correctness before detailed review of the radiograph can take place. This includes verifying aspects such as the patient identity, date of the examination, orientation markers, views taken, exposure factors used, position of the patient and the availability of previous images. 
Tutorial 2: Quality of the image. This tutorial focuses on checking the quality of the image using RIPE as proposed by Yaakob (2007):

$\mathrm{R}$ - rotation of the patient;

I - degree of inspiration;

$\mathrm{P}$ - position of the patient; and

E - exposure of the film.

Evaluation phase. Evaluation of the CBTST is one of the most important phases in a DSR project. The evaluation of the CBTST employed usability testing through the application of the System Usability Scale (SUS) (Table I) which assessed the CBTST's appropriateness for the purpose (Usability.gov, 2017). The SUS is a simple, ten-item scale giving a global view of subjective assessments of usability. The SUS was used because it has proved to be a valuable evaluation tool, which demonstrates robustness and reliability, and it has been shown to correlate well with other subjective measures of usability.
The participants were given a brief description of how to use the CBTST and were then allowed to use it. As guided by Usability.gov, the SUS was administered prior to debriefing, immediately after the participants had finished using the CBTST. The participants were encouraged to record their immediate response to each item without thinking deeply about each item. Usability.gov also recommends that if a participant cannot respond to an item on the SUS, he/ she marks the centre point of the scale, and this was the case in the current study for some participants.

Ethical considerations. Ethical approval to undertake the research study was granted by the Academic Ethics Committee of the university where the study was located (AEC64-01-2013). The four principles for resolving ethical considerations (respect for autonomy, non-maleficence, beneficence and justice) were applied throughout the study (Dhai \& Mason, 2011).

\begin{tabular}{|c|c|c|c|c|c|}
\hline & 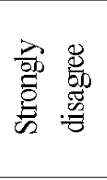 & 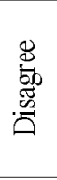 & 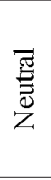 & $\underset{\mathbb{E}}{\mathbb{Z}}$ & 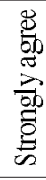 \\
\hline 1. I think that I would like to use this system frequently. & 1 & 2 & 3 & 4 & 5 \\
\hline 2. I found the system unnecessarily complex. & 1 & 2 & 3 & 4 & 5 \\
\hline 3. I thought the system was easy to use. & 1 & 2 & 3 & 4 & 5 \\
\hline 4. I think that I would need the support of a technical person to be able to use this system. & 1 & 2 & 3 & 4 & 5 \\
\hline 5. I found the various functions in this system were well integrated. & 1 & 2 & 3 & 4 & 5 \\
\hline 6. I thought there was too much inconsistency in this system. & 1 & 2 & 3 & 4 & 5 \\
\hline 7. I would imagine that most people would learn to use this system very quickly. & 1 & 2 & 3 & 4 & 5 \\
\hline 8. I found the system very cumbersome to use. & 1 & 2 & 3 & 4 & 5 \\
\hline 9. I felt very confident using the system. & 1 & 2 & 3 & 4 & 5 \\
\hline 10. I needed to learn a lot of things before I could get going with this system. & 1 & 2 & 3 & 4 & 5 \\
\hline
\end{tabular}

\section{RESULTS}

The CBTST was designed taking into consideration the SRS document and yielded a prototype as shown in Figure 2.

The key aspects during the design were the overall description which included the product perspective, product functions, user classes and characteristics, operating environment, user environment and the actual design aspects. The design also considered non-functional requirements that included performance requirements, safety requirements and security requirements. The external interface requirements considered user interfaces, hardware interfaces, software interfaces and communication protocols and interfaces. The CBTST was designed in English to be a standalone and vir- tual software which is installable on any computer that has the support of the SQL server within its network.

The access to the CBTST had to be protected using passwords linked to usernames that would also assist in checking the user profile and the relevant access levels within the platform. Each user, therefore, should launch the CBTST by using a personal password linked to the user's profile.

Three levels of user access were developed to accommodate designers, instructors and students. The launch screens for the three levels differ. The instructor launch page has been designed to have two functions, i.e. tutorial and 


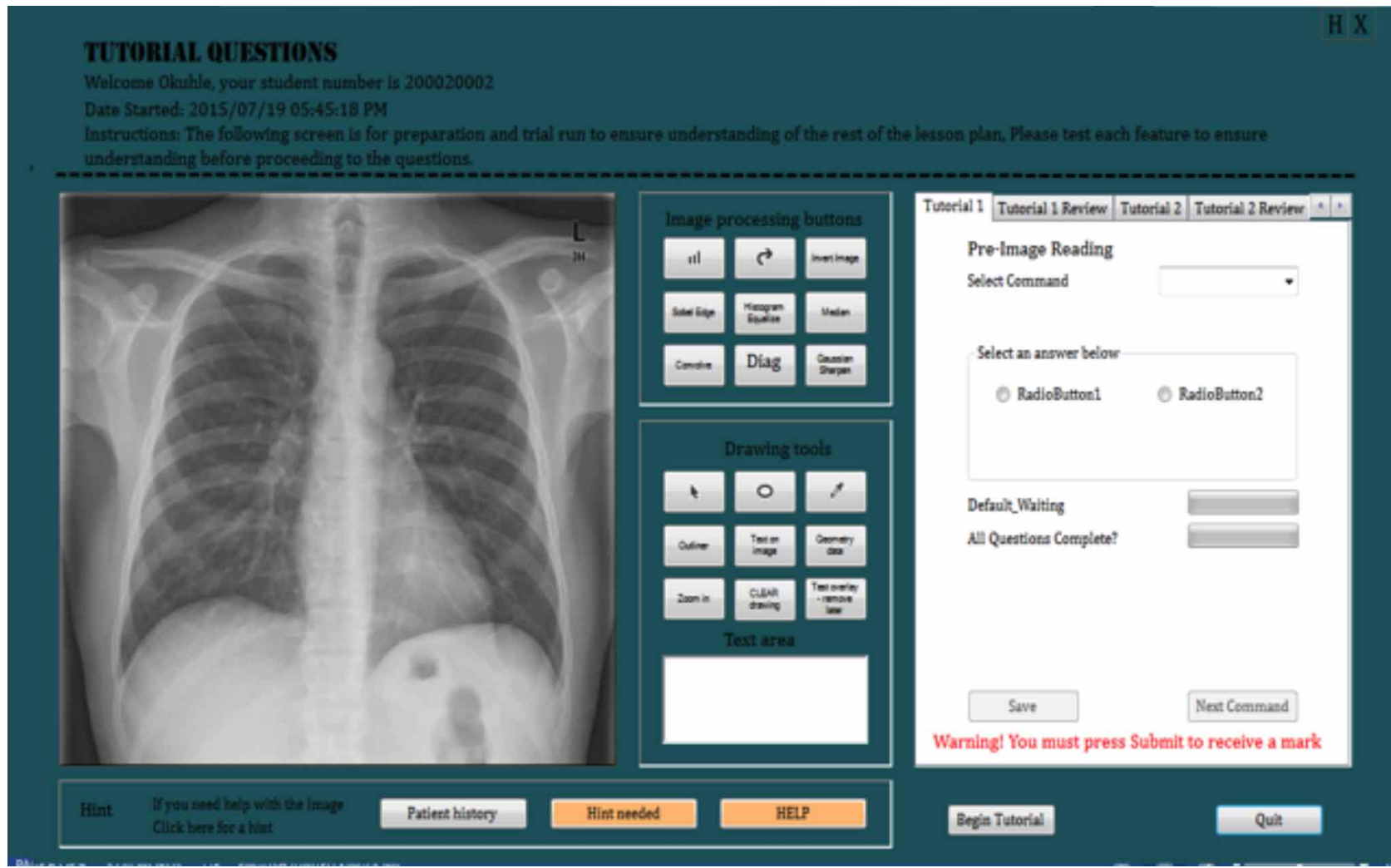

Fig. 2. Example of screen during completion of tutorial 1.

administration functions (Fig. 3). The tutorial functions allow the instructor to set up the software for various tutorials, including loading images, assigning specific tutorials to the images loaded, editing questions, providing patient history or hints and providing the answers to the tutorials

The administration function allows the instructor to add new students/staff to the platform, edit existing students, communicate with students and, most importantly, review the progress of students by reviewing their tutorial grades and answers.

The design also allows students to communicate directly with the instructor by sending communication requests that highlight to the instructor if the response needed is minor or urgent.

Furthermore, when reviewing student grades, the design requires that the instructor first select which tutorial to review and then to drill down to a student in order to review performance per image answered for the tutorial. The instructor is therefore able to track the performance of the students while identifying the areas where students have had difficulty with work completed.
The student platform has several functions, including the ability to change their user details. However, this function only allows them to edit their name and their password. It does not allow them to alter their academic level nor their student number, the latter being their primary identity. The instructor sets up the academic level of each student that is determined by his/her level of study.

Students can check the progress of their communication with the instructor using the Inquiry status function. However, should they wish to send a communication to the instructor, they need to use the Submit inquiry function or they can send the communication while using the Review answered tutorials function. Students also can review their progress, including overall marks achieved per tutorial. In addition, they can view their performance on a particular image by selecting the Image ID, which then opens the results of that particular image with the correct answers indicated. Therefore, the students can review and check where they had made mistakes, as part of their learning process.

When students are completing a tutorial, they have image processing buttons and drawing tools at their disposal. 


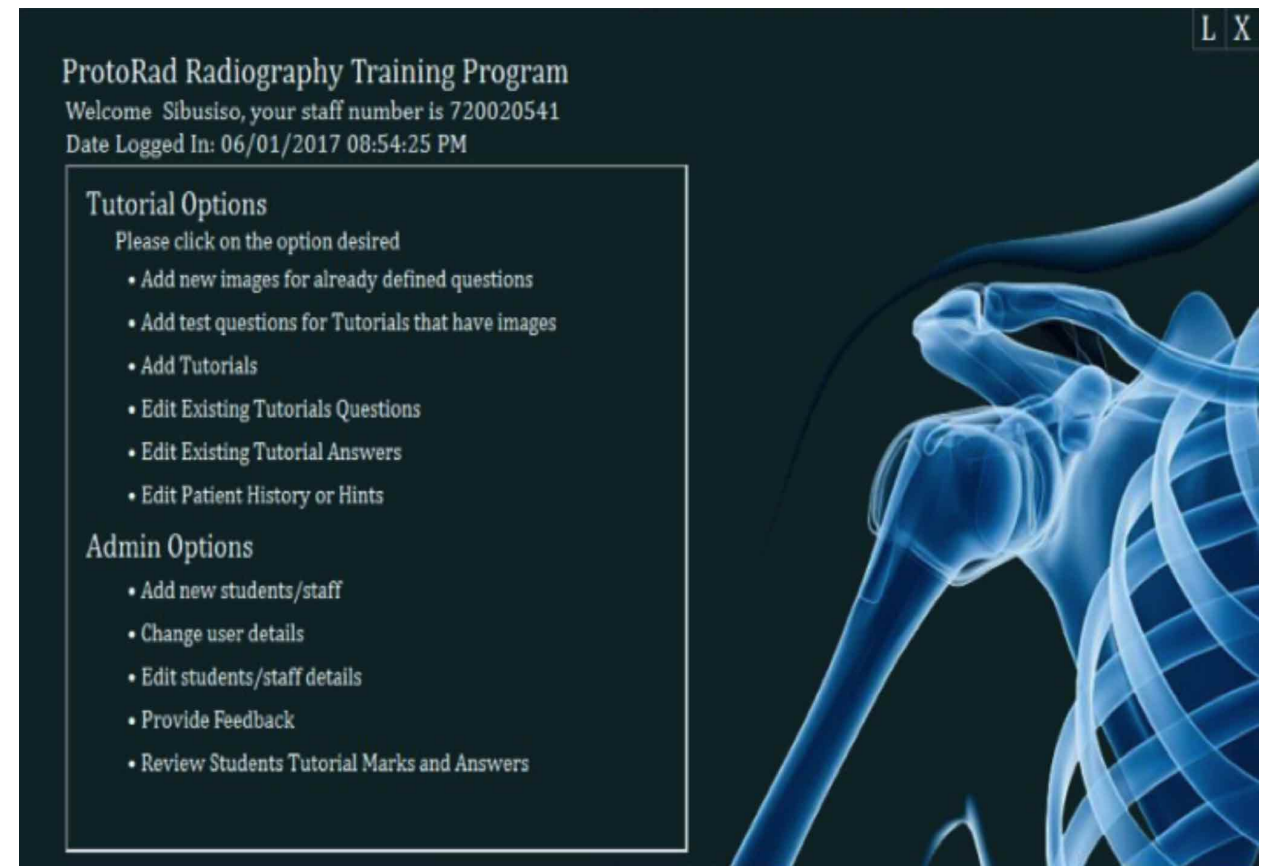

Fig. 3. Home screen for instructor function.

If they hold the mouse over a particular button/tool, it offers a description of what the function of that particular button/ tool is. The image processing buttons assist them with manipulating the appearance of the image. The drawing tools are for drawing onto and erasing drawings made on the images. The use of these buttons does not alter the original image settings. The image processing buttons are summarised in Table II below.

The drawing tools include the following:

- Straight line drawing.

- Circular drawing.

- Text on image.

- Diagonal line.

- Clear drawing which is used to clear any drawing made on the image.

Evaluation phase. Six MI educators were used in the evaluation phase as they were involved in teaching implicit skills to MI students. The number of participants was considered enough as research suggests that $95 \%$ of usability problems that will become apparent with wider implementation of a product can quickly be identified with only five or six randomly identified potential users (Sandars, 2003).

The SUS that was used for the quantitative evaluation of the CBTST yields a single number representing a composite measure of the overall usability of the system being studied. The scores for individual items are not meaningful on their own (Usability.gov).
A SUS score above 68 is an indication of good usability. Since a score of 70.1 was obtained in the current project, the CBTST has good usability. However, to derive the full meaning of the scores (since they are not a percentage even though they range from $0-100)$, they need to be normalised to a percentage. The normalising process takes raw SUS scores and generates percentile ranks (Sauro, 2011). The current study with a SUS score of 70.1 has an associated percentile score of $55-58 \%$, giving it a higher perceived usability (i.e. $>55-58 \%$ of all products tested using the SUS). This can be deemed to be of significance, and it can be concluded that the CBTST has a good usability but needs to be improved.

The participants made several comments about how they experienced the CBTST usability and these are quoted below.

\section{Positive comments}

- "I think this can work beautifully as a blended strategy where it is part of the battery of approaches - especially the function where students can be off-campus and request the facilitators help."

- "I would be very excited to use this as a scaffolding strategy in simulation education."

- "I think it is simple enough to use and I love the 'home' button if the user needs an easy way to go back."

- "I enjoyed using the software, I did not require too much time to understand how the software works, however, I do feel that using the software's different functions will take some time to understand especially how the different filtering may enhance the image or be beneficial to pattern recognition. But this will come with use and practice using the software."

- "Well done!"

\section{Negative comments}

- "The drawings of the arrows and circles were not user friendly." 


\section{Suggestions/questions for future improvements}

- "Can students also discuss among themselves if they are in different locations?"

- "I would like a measurement tool function."

- "I just found that if the screen is bigger it would be easier to use" (NB: Usability testing was done using a standard laptop; hence this suggestion of the need to use a larger screen).

These comments by the participants are useful as they highlight what worked well, what the challenges were and what could be done in future to enhance the CBTST before it is implemented widely.

Table II. Summary of image processing buttons.

\begin{tabular}{|c|c|}
\hline Button & Description of function \\
\hline Image contrast modification & $\begin{array}{l}\text { Modifies the contrast of the image to assist in displaying different } \\
\text { shades of the image. }\end{array}$ \\
\hline Image rotation & Used to rotate the image. \\
\hline Image inversion & $\begin{array}{l}\text { Creates the negative of the original image, i.e. black becomes white } \\
\text { and white becomes black. This as sists with allowing the visibility of } \\
\text { structures that may not be visible in the original image. }\end{array}$ \\
\hline Sobel edge & $\begin{array}{l}\text { Performs standardised edge detection on the image, i.e. creates image- } \\
\text { emphasising edges. This feature can be useful to detect any } \\
\text { abnormalities aligned with the continuity of the edges. }\end{array}$ \\
\hline Histogram equalisation & $\begin{array}{l}\text { Generates a standard histogram-equalised image i.e. adjusts image } \\
\text { intensities to enhance contrast using the image's histogram }\end{array}$ \\
\hline Median filtering & $\begin{array}{l}\text { Performs the median filtering of the image i.e. is a non-linear digital } \\
\text { filtering technique, often used to remove noise from an image or signal } \\
\text { in order to improve the quality of the image without altering the } \\
\text { necessary detail of the image. }\end{array}$ \\
\hline Convolve filtering (convolution kernel) & $\begin{array}{l}\text { Used for processing the images for certain features by blurring, } \\
\text { sharpening, embossing, edge detection, etc. The CBTST does not give } \\
\text { students the option to play around with the convolve button, as it gives } \\
\text { them the image in already convolved format. }\end{array}$ \\
\hline Gaussian sharpening & $\begin{array}{l}\text { Performs Gaussian sharpening of the image and this typically reduces } \\
\text { image noise and detail. }\end{array}$ \\
\hline Diagonal & $\begin{array}{l}\text { Allows the students to draw a diagonal line from the top right-hand } \\
\text { corner of the image to the bottom left-hand corner of the image. }\end{array}$ \\
\hline Zoom-in & Used to magnify the image to an area of interest. \\
\hline
\end{tabular}

\section{DISCUSSION}

The purpose of this study was four-fold: to design 1) an authentic (original and genuine) tool; 2) that can be used to provide feedback to students while enhancing training; 3) allow for student-paced training while providing for repetitive stimulus to enhance implicit skills; and 4) be a user-friendly tool that students can use without needing a full-time instructor to be present. The study contributed MI education, scientific research and technology development.
The CBTST itself is a product (instantiation), with the specific intent to improve the implicit skills of student radiographers in pattern recognition. It was designed as an authentic product that can provide feedback and allow communication between the students and the instructor.

Importantly, the study was conducted using a research methodology (DSR) (scientific contribution) that is generally 
used for IS and is seldom used in disciplines such as health sciences. The first major contribution of the study is therefore pioneering the use of this methodology in the field of MI. This is a significant contribution in the light of recent developments in radiology where the future is beginning to show that Industry 4.0, specifically AI, has a major role to play in the future for learning, teaching and assessment, and image reporting. This agrees with Lindner (2017) who asserts that health care organisations "should be aware of the ongoing digital transformation and consider how to translate their business needs into analytics approaches and new digitalization strategies". The CBTST developed in this study is an excellent tool to align with the analytics approaches and new digitalisation strategies that Lindner refers to. In addition, the CBTST has the potential to be a technique that could be used to replace and amplify real experiences while evoking substantial aspects of the real world in an interactive manner (Jones et al.; Shanahan).

The scientific contribution of this study will therefore have an impact on the future development of the CBTSTs and similar resources that are aligned with the technological developments in MI, with a specific focus on enhancing the implicit skills of students by using CBTST. In addition, the study contributes to the growing pool on the use of simulation in MI using computer-based approaches (Shanahan).

The major limitation of this study is that the CBTST was not ready (within the period of the study) for evaluation with students as theinstitutional network platform was not accommodating for installation in the computer laboratories to give access to the students. However, the approaches used to evaluate the CBTST were enough to pronounce on the utility thereof.

\section{CONCLUSION}

The design of the CBTST for plain chest imaging, using the current pattern recognition guidelines for undergraduate students, has contributed to the current developments in virtual teaching tools available for MI education. In addition, the study shows that CBTSTs can be developed to enhance student learning, teaching and assessments. The CBTST comprises important educational tools that encourage student-centred autonomous learning, making it suitable for use in a constructivist approach to teaching and learning. The CBTST also has important educational aspects that include feedback to students and communication with the lecturer/instructor. This is an important educational approach in terms of learner engagement.
The CBTST that was developed does not preclude application to other anatomical areas if the support material incorporated is adapted.

\section{ACKNOWLEDGEMENTS}

Dr. HA Lawrence (University of the West England, United Kingdom) and Prof AL Nel (University of Johannesburg, South Africa) who were the promoters of this project. Mailto: rsn@odont.au.dk

MDLETSHE, S. \& OLIVEIRA, M. Desarrollo de una herramienta de simulación computacional de enseñanza de apoyo a los educadores de imagen médica en la enseñanza del patrón de reconocimiento. Int. J. Morphol., 38(5):1258-1265, 2020.

RESUMEN: El objetivo de este estudio de investigación en ciencias de diseño (DSR) fue desarrollar una herramienta de simulación de enseñanza basada en computadora (CBTST) para capacitar a los estudiantes en el reconocimiento de patrones de tórax a través de la imagenología médica. Una metodología DSR utilizada en el diseño del CBTST implicaba las siguientes fases: 1) conciencia del problema (diseño de la propuesta); 2) sugerencia; 3) desarrollo; 4) evaluación; y 5) conclusión. El CBTST se diseñó con Microsoft Visual Studio, que opera en el servidor de Structured Query Language. El CBTST diseñado se evaluó utilizando la escala de usabilidad del sistema (SUS) y educadores de IM. La evaluación CBTST diseñada arrojó un puntaje promedio de 70,1 que excedió el puntaje de 68 que generalmente se acepta para indicar que el CBTST tiene buena usabilidad. El CBTST demostró ser una herramienta auténtica, fácil de usar y que permite la comunicación y la retroalimentación entre el educador y los estudiantes. Se prevé que la implementación de esta herramienta mejorará la formación futura de los estudiantes de IM en el reconocimiento de patrones y contribuirá de manera importante al desarrollo actual del uso de la simulación basada en computadora.

PALABRAS CLAVE: Reconocimiento de patrones; Desarrollo de software; Simulación computacional de enseñanza; Imágenes médicas; Habilidades implícitas.

\section{REFERENCES}

Chen, P. H.; Roth, H.; Galperin-Aizenberg, M.; Ruutiainen, A. T.; Gefter, W. \& Cook, T. S. Improving abnormality detection on chest radiography using game-like reinforcement mechanics. Acad. Radiol., 24(11):142835, 2017.

Dhai, A. \& Mason, D. M. Bioethics, Human Rights and Health Law: Principles and Practice. Cape Town, Juta \& Company, 2011.

Eisenberg, R. L. \& Johnson, N. M. Comprehensive Radiographic Pathology. $6^{\text {th }}$ ed. St. Louis, Mosby, 2015.

European Society of Radiology 2009. The future role of radiology in healthcare. Insights Imaging, 1(1):2-11, 2010. 
Fornell, D. New Trends and Technology in Radiology. Trends and Insights from RSNA 2012. itn Imaging Technology News, 2012. Available from: https://www.itnonline.com/article/new-trends-and-technologyradiology

Herring, W. Learning Radiology: Recognizing the Basics. $3^{\text {rd }}$ ed. Philadelphia, Elsevier, 2016.

Jones, F.; Passos-Neto, C. E. \& Braghiroli, O. F. M. Simulation in medical education: brief history and methodology. Princ. Pract. Clin. Res., 1(2):46-54, 2015

Lindner, M. Healthcare 4.0 (In Real Life). Siemens Healthineers, 2017. Available from: https://www.healthcare.siemens.com/magazine/msodigitalization-healthcare.html

Malathi, B. G.; Sandhu, J. K.; Bhat, Y. M. \& Nagaraju, K. K. Significance of skill reinforcement in undergraduate teaching: a medical college experience. Int. J. Sci. Res., 4(7):108-11, 2016.

Pesapane, F.; Volonté, C.; Codari, M. \& Sardanelli, F. Artificial intelligence as a medical device in radiology: ethical and regulatory issues in Europe and the United States. Insights Imaging, 9(5):745-53, 2018.

Rockall, A.; Hatrick, A.; Armstrong, P. \& Wastie, M. Diagnostic Imaging. $7^{\text {th }}$ ed. West Sussex, Wiley-Blackwell, 2014.

Sandars, J. E. E-learning: the coming of age. Educ. Prim. Care, 14:1-5, 2003.

Sauro, J. Measuring Usability with the System Usability Scale (SUS). MeasuringU, 2011. Available from: https://measuringu.com/sus/

Shanahan, M. Student perspective on using a virtual radiography simulation. Radiography, 22(3):217-22, 2016.

Shiraishi, J.; Katsuragawa, S.; Ikezoe, J.; Matsumoto, T.; Kobayashi, T.; Komatsu, K.; Matsui, M.; Fujita, H.; Kodera, Y. \& Doi, K. Development of a digital image database for chest radiographs with and without a lung nodule: receiver operating characteristic analysis of radiologists' detection of pulmonary nodules. AJR Am. J. Roentgenol., 174:71-4, 2000.

Usability.gov. System Usability Scale (SUS). Washington (DC), U.S. Department of Health \& Human Services, 2020. Available from: https:/ /www.usability.gov/what-and-why/glossary/system-usability-scalesus.html

Vaishnavi, V.; Kuechler, W. \& Petter, S. (Eds.). Design Science Research in Information Systems. In: Association for Information Systems, 2019. Available from: http://www.desrist.org/design-research-in-informationsystems/

Yaakob, W. Interpreting Chest X-Rays. PatientCare, 2007. Available from: https://www.patientcareonline.com/view/interpreting-chest-X-rays

\section{Corresponding author: Sibusiso Mdletshe, PhD 06 IL Palazzone \\ Estate 586 Muriel Road \\ Ruimsig, Amorosa, 1724 \\ Johannesburg \\ SOUTH AFRICA}

Email: sibusisom72@gmail.com sibusisomdletshe@yahoo.com

Received: 21-03-2020

Accepted: 04-05-2020 